\title{
DE AOMORI AO SHURI: EXCERTOS DO DIALETO DA LÍNGUA JAPONESA
}

\author{
Kaoru Tanaka de Lira \\ Marcus Tanaka de Lira ${ }^{2}$
}

Resumo: O território japonês, formado por várias ilhas montanhosas, apresenta uma grande variação dialetal, por vezes, ininteligíveis para outros habitantes do país. Visando suprir a falta de materiais que descrevam a variedade dialetal encontrada no Japão que possam ser consultados por alunos dos diferentes cursos universitários de formação de professores de língua japonesa em atividade no Brasil, as páginas a seguir descrevem alguns dos diferentes aspectos da variação dialetal no arquipélago. Após a introdução do conceito de dialeto, língua padrão e língua comum, serão descritas as divisões dialetais do Japão, e serão expostas algumas das características de variação fonética, fonológica e morfossintática entre os dialetos da língua, assim como será dado um pequeno retrato dos dialetos de Tsugaru e Tosa.

Palavras-Chave: Variação dialetal; língua japonesa; kagyûkô, propagação radial; Okinawa-go;

\begin{abstract}
The Japanese territory, constituted by several mountainous islands, shows a wide variety of dialects, often unintelligible to other inhabitants of the country. Hoping to solve the dearth of material describing the variety of dialects found in Japan that may be useful to students of different university-level Japanese language courses in activity in Brazil, the following pages describe briefly some of the different aspects found among Japanese dialects in the archipelago. After the introduction of the concept of dialect, standard language, common language, and what the dialect divisions in Japan are, there is an explanation concerning language variation at the phonetic, phonological, and morphosyntactic levels of the language, as well as a sample of the Tsugaru and Tosa dialects.
\end{abstract}

Keywords: Dialect variation; Japanese language; kagyûkô; Radial propagation; Okinawa-go

1 Professora Mestre do Departamento de Línguas e Literatura Estrangeira, Instituto de Ciências Humanas e Letras - ICHL, Universidade Federal do Amazonas - UFAM, Manaus, Brasil; kaorufreedom@gmail.com

2 Professor Doutor do Departamento de Línguas Estrangeiras e Tradução - LET-UnB, Instituto de Letras - IL, Universidade de Brasília - UnB, Brasília, Brasil; lira.marcus@gmail.com 


\title{
1. O que é um dialeto?
}

Antes de qualquer coisa, é preciso discutir o conceito de dialeto (hôgen 方言em japonês). Quando se fala em dialetos, normalmente se fala de uma variedade, uma subdivisão de uma língua. Sendo assim, há a necessidade de se conceituar o que é língua. Na realidade não há um consenso entre os linguistas sobre o que é uma língua. Havendo dificuldades em se conceitua-la, consequentemente, há também dificuldades em conceituar o que é um dialeto e quando um dialeto passa a ser considerada uma nova língua (CHAMBERS e TRUDGILL, 1998, p. 03). Contudo, serão colocados abaixo os conceitos de alguns teóricos.

Para McWhorter (2004) o conceito de língua é um conceito artificial e arbitrário:

"Conseguimos entender o que são dialetos apenas ao nos livrar da concepção errônea comum de que o dialeto é uma versão degradada da língua padrão. O que cria os dialetos não é preguiça, mas mudança linguística simples". (MCWHORTER, 2004, p. 7)

Para Chambers \&Trudgill (1998), dialeto se refere às variedades que são gramaticalmente (e talvez lexicalmente), assim como fonologicamente diferentes de outras variantes (2004).

\begin{abstract}
“A não ser que haja uma condição especial, a diferença lingüística é pequena entre regiões próximas, e maior entre localidades distantes, chegando a ponto de os falantes não se entenderem. Assim são formadas diferentes línguas, mas não existe uma regra para se definir quanta diferença seria necessário para que duas variantes sejam consideradas duas línguas ou dois dialetos.” (KUNO, 2006, p. 60)
\end{abstract}

No Japão, é encontrado em um manuscrito chinês da Era Heian o registro mais antigo da palavra hôgen, dialeto. Esta é usada com o significado mais próximo a língua regional (SUZUKI, HAYASHI, et al., 1995, p. 232).

É importante, antes de começar a se falar nos dialetos do Japão, estar consciente que a variação ocorre em todos os níveis da língua. Bagno (2007) divide em 6 níveis sendo eles: (1) variação fonética-fonológica; (2) variação morfológica; (3) variação sintática; (4) variação semântica; (5) variação lexical e (6) variação estilísticopragmática (BAGNO, 2007, p. 39-40). Para os dialetos da língua japonesa, trataremos apenas das 5 primeiras variações, pois a variação estilístico-pragmática pode ser muito específica para o presente resumo que pretende descrever de forma geral os dialetos do Japão.

3 Original em inglês: "We can understand what dialects are only by shedding the common misconception that a dialect is a degraded version of the standard language. What creates dialects is not sloth but simple language change." 


\section{Dialetos do Japão}

Segundo Shibatani (1990), o Japão é extremamente rico em variações dialetais (p.185). Suzuki et al. (1995) respalda afirmando que a língua japonesa, mesmo comparada às outras línguas existentes no mundo, é classificada em um grupo com grandes variações dialetais (p. 238). Ainda segundo Shibatani (1990), as distinções são tamanhas que, muitas vezes, são mutuamente incompreensíveis entre falantes de dialetos distintos. Os falantes do dialeto de Kagoshima, ao sul da ilha de Kyûshû, por exemplo, não são compreendidos pela maioria das pessoas da ilha principal, Honshû. Do mesmo modo, as pessoas de Aomori e Akita não são compreendidas por pessoas da área metropolitana de Tôkyô ou qualquer lugar do oeste do Japão (SHIBATANI, 1990, p. 185). Porém, a comunicação entre falantes de dialetos distintos no arquipélago é possível graças ao uso do que é chamado de kyôtsĥgo (共通語), ou seja, a língua comum. Desse modo, é necessária uma breve discussão sobre o conceito de língua-padrão, hyôjungo (標準語) e língua comum da qual se opõe aos dialetos.

\section{Língua padrão e língua comum}

Segundo Shibatani (1990), a existência de dialetos no Japão já era relatada na antologia de poemas japonês, o Man'yôshû (759 A.C.), onde se encontram canções que fazem distinção dos dialetos do Leste e Oeste do arquipélago.

Há indicações de que as pessoas do início do século XVII tinham uma ideia razoavelmente clara de qual dialeto deveria ser considerado "padrão". Fato esse que pode ser visto nas descrições da língua japonesa feitas pelo missionário cristão Rodriguez que nota que o "verdadeiro" japonês coloquial é aquele usado na corte da capital Kyôto. O glossário onde está listado o que os ditos significam na expressão de Kyôto é outra evidência de que o dialeto da antiga capital era considerado padrão (SHIBATANI, 1990).

Mesmo quando a sede do governo foi transferida para Edo (atual Tôkyô) em 1603, o status do dialeto de Kyôto não foi ameaçado imediatamente. Isso porque a antiga capital e as cidades vizinhas, como Ôsaka, estavam incluídas no centro econômico e cultural que dominava o resto do país. Entretanto, o domínio linguístico do dialeto de Kyôto foi ruindo de acordo com a consolidação de Edo. Com o passar do tempo, a ideia de que o dialeto de Edo como língua padrão se espalhou durante a era Meiji reforçado pela nova capital, Tôkyô.

No Japão, as palavras língua padrão (標準語) e língua comum (共通語) são frequentemente usadas sem distinção e sem causar muitas complicações, porém entre os pesquisadores essa diferença é bem feita (SUZUKI, HAYASHI, et al., 1995, p. 233).

Segundo Kuno (2007), língua padrão é algo determinado de forma artificial, uma forma ou modelo que devem existir onde se estabeleça um critério de 
comparação ou marco (p.8). Assim, no Japão, língua padrão é uma forma idealizada que não existe de fato (SUZUKI, HAYASHI, et al., 1995, p. 233; KUNO, 2006, p. 61). ${ }^{4}$

Inicialmente, a necessidade de uma língua padrão também surgiu na confecção de livros didáticos para a educação básica. Contudo, a disseminação da língua padrão fez surgir um complexo de inferioridade entre os falantes de dialetos periféricos e trouxe uma devastação linguística. $\mathrm{O}$ incidente mais notório do preconceito em relação aos dialetos periféricos foi hôgen fuda, uma placa feita de madeira onde era escrito "dialeto" que era pendurado no pescoço das crianças que usassem dialetos na escola (SHIBATANI, 1990, p. 186).

Em contrapartida, a língua-comum surgiu de forma natural e espontânea, e difere da língua padrão, pois esta é produto de uma idealização, virtual, ao passo que aquela constitui uma linguagem realmente existente. O termo língua comum foi utilizado no lugar de língua padrão pelo National Institute for Japanese Language and Linguistics (NINJAL) após a Segunda Guerra Mundial e difundida pelos profissionais de ensino da língua pátria (kokugô) e seus pesquisadores (SUZUKI, HAYASHI, et al., 1995, p. 233). A língua comum foi adotada para que pessoas de diferentes dialetos pudessem se comunicar e é usada em ocasiões formais com desconhecidos.

\section{Divisão dialetal do Japão}

Apesar de haver várias divisões dialetais do arquipélago japonês, o mais popular e difundido na linguística japonesa é a divisão de Tôjô Misao (1954) ${ }^{5}$ (SHIBATANI, 1990, p. 187). Tôjô divide os dialetos do arquipélago como demonstrado no mapa (figura 1) e no diagrama abaixo (figura 2).

\footnotetext{
4 我が国において「標準語」とは現実には存在しない理想体ともでもいうべきものである。 (SUZUKI, HAYASHI, et al., 1995, p. 233) 


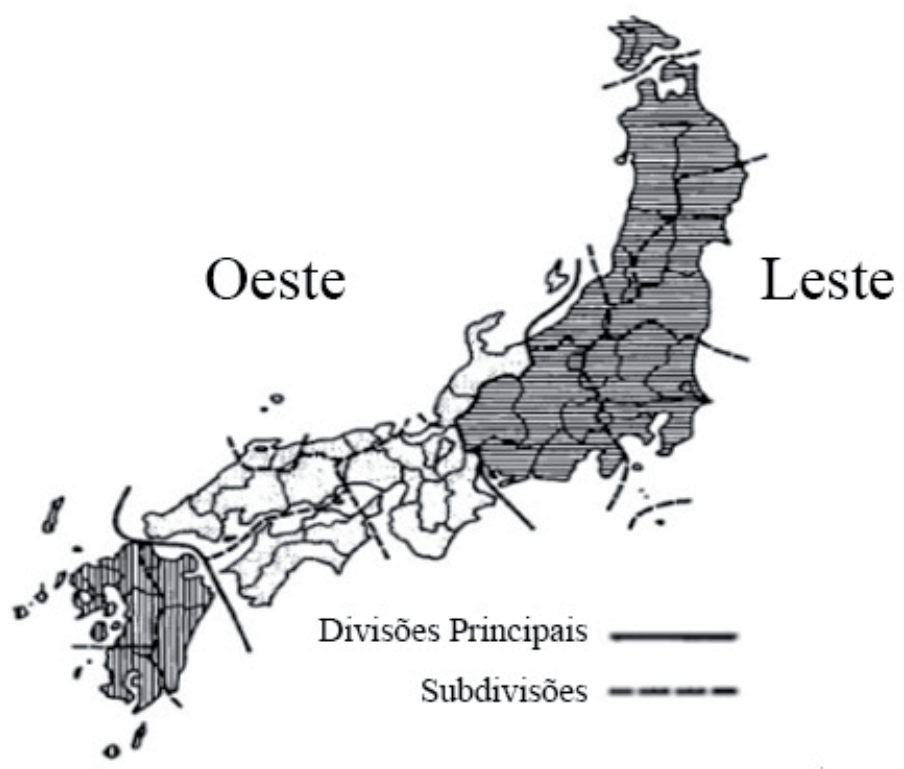

Figura 1: Divisão geográfica dos dialetos do Japão (SHIBATANI, 1990, p.189)

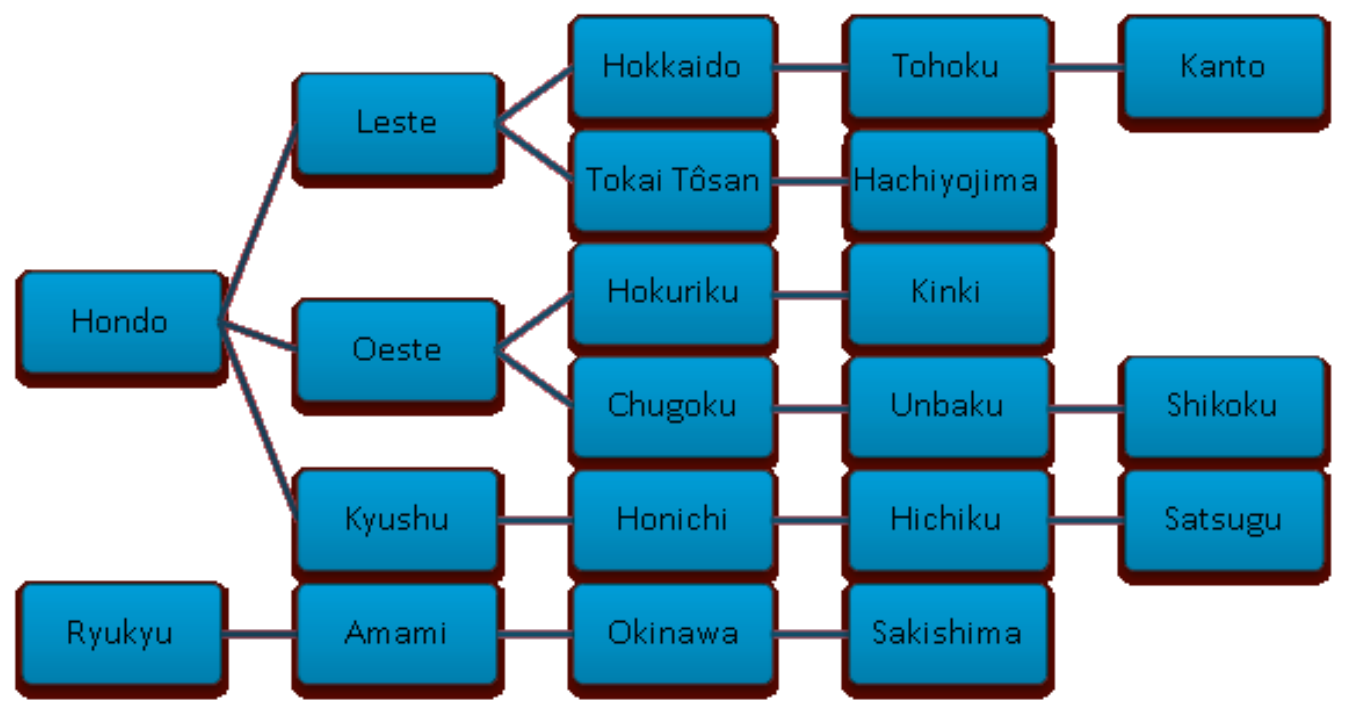

Figura 1: Divisão dialetal do Japão (SUZUKI, HAYASHI, et al., 1995, p. 242) 
De uma maneira geral, podem-se dividir as variantes da língua japonesa em dialetos da ilha principal (Honshû) e de Ryûkyû (Okinawa). E os dialetos do Leste e Oeste incluindo os dialetos de Kyûshû nos do Oeste. Na sequência, serão descritos as características gerais das divisões maiores.

\section{Língua de Ryukyu}

A província da atual Okinawa e as ilhas ao seu redor formavam o reino de Ryûkyû com capital em Shuri 首里(atual Naha). A língua usada neste reino era chamada de Ryûkyû-go (Ryûkyûan ou Luchuan) (SHIBATANI, 1990, p. 189). Pode se dizer que o fato de ser conhecido como Ryûkyû-go (língua de Ryûkyû) e não de Ryûkyû-hôgen (dialeto de Ryûkyû) já demonstra a distância linguística desta com a língua falada em Honshû, mas mesmo sendo uma língua diferente, seus dialetos e sua origem comum com a língua japonesa contemporânea podem ajudar a entender melhor os dialetos japoneses. Para compreender melhor sobre esta língua, entretanto, é preciso percorrer, mesmo que de forma sucinta, pela história da atual província de Okinawa.

O reino de Ryûkyû foi estabelecido no séc. XV e em 1609, passou a ser parte do clã Shimizu de Kagoshima, Kyûshû. Posteriormente, em 1879 na Era Meiji, tornou-se uma das províncias do Japão e só então recebeu o atual nome, Okinawa-ken (Província de Okinawa). Porém, após a segunda guerra mundial passou a ser ocupado pelos Estados Unidos, país que dominou as ilhas por 27 anos sendo devolvida ao governo japonês apenas em 1972.

Desse modo, apesar de por uma perspectiva histórica o Ryûkyû-go ser considerado uma língua independente do japonês, alguns estudiosos o consideram uma língua irmã da língua japonesa (CHAMBERLAIN Apud SHIBATANI, 1990, p.189). Suzuki et al. afirma no livro Gaisetsu Nihongo Gaku que a língua em questão se separou do protolíngua japonesa, possivelmente, entre os séculos II a VII. Por um lado, a variação manteve algumas formas do japonês antigo e por outro desenvolveu mudanças peculiares, explicando o porquê de haver diferença considerável entre as duas línguas (p.251). Há teóricos que comparam a relação entre as duas línguas com a do espanhol com o italiano ou do francês com o italiano. Isso se deve a semelhança da língua japonesa com a língua em questão que conserva características fonológicas, sintáticas e lexicais do japonês antigo.

\subsection{Variações morfossintáticas:}

Uma das peculiaridades da língua de Okinawa é que a flexão shushikei se distingue da rentaikei. As duas se flexionam de maneira similar no japonês contemporâneo. Porém, a língua de Okinawa mantem essa característica que também existia na língua japonesa antiga. Usando os termos do ensino de japonês como segunda língua, é como se tivessem duas formas dicionário: Uma para finais de frases e a outra quando estão em função adjetiva. 
Exemplo ${ }^{6}$ :

あのひとがかく 絵 はきれいだ。

ano hito ga KAK-U e wa kirei da.(língua comum)

3.SG SUJ desenhar-Ñ.PSD.RTK desenho TOP bonito COP

"O desenho que aquela pessoa desenha é bonito"

あのひとは きれいな な絵をを か。

ano hito wa kirei na e wo KAK-U. (língua comum)

3.SG TOP bonito ADJ desenho OBJ desenhar-Ñ.PSD-SSK

"Aquela pessoa desenha um desenho bonito"

Na língua de Okinawa, o verbo kaku (desenhar/ escrever) nas frases dos exemplos acima seria dito, respectivamente, [katfuru] e [katfun]. Assim, o verbo se flexiona da seguinte maneira:

\begin{tabular}{|l|l|l|}
\hline Flexão & Língua comum & Ryûkyû \\
\hline Mizenkei & 書かない (kakanai) & {$[$ kakaN] } \\
\hline Ren'yôkei & 書いた (kaita) & {$[$ katfan] } \\
\hline Shûshikei & 書く(kaku) & {$[$ katfun] } \\
\hline Rentaikei & 書く(kaku) & {$[$ katfuru $]$} \\
\hline Katekei & 書くならば(kakunaraba) & {$[$ katfure: $]$} \\
\hline Meireikei & 書け(kake) & {$[$ kaki] } \\
\hline
\end{tabular}

\subsection{Variações lexicais:}

A teoria de que a língua de Ryûkyû e o japonês tiveram a mesma origem são reforçadas também pelos aspectos lexicais, pois muitas palavras da antiga língua japonesa foram preservadas na língua de Ryûkyû, mostradas abaixo nos dialetos de Shuri e Tôkyô:

6 Abreviaturas utilizadas: $3 \mathrm{SG}=$ terceira pessoa do singular; $\mathrm{SUJ}=$ sujeito; $\mathrm{N} . \mathrm{PSD}=$ não-passado; $\mathrm{RTK}=$ rentaikei; $\mathrm{ADJ}=$ adjetivo; $\mathrm{TOP}=$ tópico; $\mathrm{OBJ}=$ objeto; $\mathrm{COP}=$ cópula; $\mathrm{SSK}=$ shuushikei 
Exemplos:

\begin{tabular}{|c|c|c|}
\hline Shuri & Tôkyô & Significado \\
\hline tudzi & tsuma & esposa \\
\hline Wan & watashi & eu \\
\hline warabi $^{7}$ & kodomo & criança \\
\hline
\end{tabular}

\subsection{Variações fonéticas:}

Na língua de Ryûkyû, as vogais /e/ e /o/ da língua-padrão são equivalentes às vogais /i/ e /u/ (SUZUKI, HAYASHI, et al., 1995, p. 252).

\begin{tabular}{|c|c|c|}
\hline Shuri & Tôkyô & Significado \\
\hline Ami & ame & chuva \\
\hline Akiti & akete & abrir \\
\hline Sudi & sode & manga \\
\hline
\end{tabular}

Apesar de possuírem apenas três vogais curtas $(/ \mathrm{a} /, / \mathrm{i} /, / \mathrm{u} /)$, existe no dialeto de Shuri a vogal longa [o:] derivada de [au], [ao] e [ou]. Da mesma maneira, existe a vogal longa [e:] derivada de [ai] e [ae] (SHIBATANI, 1990, p. 194). Este fenômeno será melhor descrito posteriormente.

Em Honshû a consoante [p] virou [ $\varphi]$ no século VIII e eventualmente em [h]. Vários dialetos de Ryûkyû mantiveram o [p] (SHIBATANI, 1990, p. 194). Abaixo alguns exemplos:

\begin{tabular}{|c|c|c|}
\hline Shuri & Língua Comum & Significado \\
\hline pPiru & hiru & durante o dia \\
\hline pana & hana & flor \\
\hline pi & hi & fogo \\
\hline pa & ha & folha \\
\hline
\end{tabular}

Em Yaeyama, o [p] é realizado como um [f], fricativo lábio dental, em alguns contextos, contrastando entre si (SHIBATANI, 1990, p. 194). Exemplos:

7 A palavra /warabe/, na língua comum, significando criança é mantida em palavras como warabe uta, música infantil. 


\begin{tabular}{|c|c|c|}
\hline Yaeyama & Língua Comum & Significado \\
\hline puni & hone & osso \\
\hline funi & fune & navio \\
\hline
\end{tabular}

Essas características dos dialetos da língua de Ryûkyû mostram que os traços da antiga língua japonesa ainda mantidos em Okinawa são a melhor ilustração da teoria de que as áreas periféricas mantêm formas antigas da língua (SHIBATANI, 1990, p. 195).

\section{Oposição Leste-Oeste}

Os dialetos das ilhas principais (Hokkaido; Honshû, Kyûshû e Shikoku) são divididas em três grandes grupos, Leste, Oeste e Kyûshû. Porém, há um abismo dialetal que divide o Leste do Oeste de forma que alguns dialetologistas veem a possibilidade de dividir as ilhas principais em dois grupos, sendo Kyûshû incluído na parte oeste (SHIBATANI, 1990, p. 196).

A seguir as principais diferenças entre os dialetos do Leste e a do Oeste.

\subsection{Variações morfossintáticas:}

Segundo Shibatani (1990), os exemplos frequentemente citados no domínio morfossintático incluem:

1) o imperativo dos verbos terminados em vogal (verbos do grupo II);

\begin{tabular}{|c|c|c|}
\hline Oeste & Leste & Significado \\
\hline miyo / mi: & miro & Ver \\
\hline okiyo / oki: & okiro & Acordar \\
\hline
\end{tabular}

2) a forma ta/te de verbos terminados em う, dos verbos do I;

\begin{tabular}{|c|c|c|}
\hline Oeste & Leste & Significado \\
\hline haroota & haratta & Pagar \\
\hline koota & katta & Comprar \\
\hline
\end{tabular}


3) a forma adverbial dos adjetivos;

\begin{tabular}{|c|c|c|}
\hline Oeste & Leste & Significado \\
\hline $\begin{array}{l}\text { hiroonaru / } \\
\text { hiruunaru }\end{array}$ & hiroku naru & $\begin{array}{c}\text { ficar } \\
\text { espaçoso }\end{array}$ \\
\hline takoonaru & takakunaru & ficar caro \\
\hline $\begin{array}{c}\text { mezurasjuunaru/ } \\
\text { mezurasiinaru }\end{array}$ & mezurasikunaru & Ficar raro \\
\hline
\end{tabular}

4) as formas negações;

\begin{tabular}{|c|c|c|}
\hline Oeste & Leste & Significado \\
\hline sen/siehen & shinai/shine: & não fazer \\
\hline okin/okihen & $\begin{array}{c}\text { okinai/ } \\
\text { okine: }\end{array}$ & não acordar \\
\hline
\end{tabular}

5) as formas de cópula;

Exemplo: da (leste) - zya/ ya (oeste)

6) a forma dos verbos terminados em su.

\begin{tabular}{|c|c|c|}
\hline Oeste & Leste & Significado \\
\hline otoita & otoshita & Derrubar \\
\hline daita $^{8}$ & dashita & Tirar \\
\hline
\end{tabular}

\subsection{Variações lexicais:}

Abaixo alguns exemplos de variações lexicais:

\begin{tabular}{|l|l|l|}
\hline Oeste & Leste & Significado \\
\hline kemuri/keburi & kemu / kebu & Fumaça \\
\hline nasubi & nasu & berinjela \\
\hline nanuka & nanoka & sete dias \\
\hline oru & iru & estar/existir (seres animados) \\
\hline ototsui & ototoi & anteontem \\
\hline
\end{tabular}

8 Realização frequente na região de Chûbu. 


\begin{tabular}{|l|l|l|}
\hline shiasatte & yanoasatte & daqui há três dias \\
\hline me & manako & olho \\
\hline akai & akarui & claro \\
\hline
\end{tabular}

\subsection{Variações fonéticas:}

Ainda segundo Shibatani (1990), há três diferenças marcantes entre os dialetos do Leste e do Oeste nos aspectos fonéticos.

1. Labialização do /u/ - a vogal /u/ é não-arredondada no Leste [u] e arredondada no Oeste $[\mathrm{u}]$.

2. Alongamento de vogal em palavras monomoráicas - no Oeste, palavras de uma mora são alongadas e pronunciadas em duas moras. Por exemplo, em Tôkyô "árvore" e "nome" que são pronunciadas $k i$ e $n a$, respectivamente. Em Ôsaka, estas são pronunciadas kii e naa.

3. Acento tonal - na região leste, o chamado sistema de acento de Tôkyô é difundido enquanto o no oeste os sistemas de Kyôto e Ôsaka dominam as áreas centrais, como veremos posteriormente.

Fica claro que há uma divisão linguística profunda entre o Leste e o Oeste do Japão. A linha corre entre as prefeituras de Niigata e Toyama ao norte de Shizuoka e ao sul de Aichi.

As isoglossas ${ }^{9}$ são mais marcadas entre a região norte e central enquanto eles tendem a serem mais espalhadas na região sul. Isso se deve a cadeia de montanhas conhecida como Alpes Japoneses que correm verticalmente na região central e também porque tem tido maior tráfico no lado pacífico comparado ao lado do Mar do Japão. Assim, as características geográficas de toda a região têm contribuído na criação da oposição Leste-Oeste não só na esfera linguística, mas também em outros campos socioculturais (SHIBATANI, 1990, p. 198).

O que é mais interessante é o fato de que nas duas regiões, leste e oeste, há áreas que demonstram características de fala da outra região. Por exemplo, na região Leste, os falantes de Tôkyô (Yokohama) diferem em alguns aspectos do resto do dialeto do Leste. Em particular na fala de Tôkyô incluem alguns traços da região de Kyôto (Ôsaka). Além disso, no Oeste do Japão há ocorrências esporádicas de características dos falantes do Leste. Algumas dessas misturas de traços dialetais podem ser facilmente explicadas como casos de empréstimos. Os traços de Kyôto na fala de Tôkyôo-Yokohama é um dos casos.

9 Isoglossa: linha que, num mapa linguístico, indica as áreas em que se concentram determinados traços linguísticos; pode ser fônica, morfológica, léxica ou sintática, de acordo com a natureza do elemento linguístico focalizado (Dicionário eletrônico Houaiss da língua portuguesa). 
A fala de Kyôto-Ôsaka conservou o prestígio mesmo depois de o governo ter se mudado para Tôkyô, no início do século XVII e o status de língua do centro cultural e econômico foi poderoso o suficiente para influenciar a língua da nova capital. Segundo Shibatani (1990), a fala de Tôkyô se destaca do resto dos dialetos da região Leste em alguns aspectos. Enquanto na região Leste, em geral, tendem a juntar a sequência de vogais /ai/, /oi/ e /ui/ em [e:], [e:] e [i:], respectivamente, a fala de Tôkyô e de Kyôto pronuncia-se sem essa junção (p. 199).

Porém, Kuno (2006) afirma que a fusão das vogais seguidas, descrita acima, ocorre nos dialetos das regiões de Tokai, Chûgoku e Kyûshû e pode ser considerada maioria, com exceção da região de $\operatorname{Kinki}^{10}$ (p. 62), onde se localiza Kyôto e Ôsaka já citada por Shibatani. Assim, a fusão não é uma característica exclusiva da região Leste.

Exemplo:

\begin{tabular}{|c|c|c|}
\hline Kyôto/ Ôsaka/ Tôkyô & Leste & Significado \\
\hline takai & take: & caro (preço) \\
\hline sugoi & suge: & formidável \\
\hline samui & sami: & frio \\
\hline
\end{tabular}

A primeira vista, talvez seja complexo imaginar como o [ai] ou [ae] viram [e:]. Entretanto, é preciso ressaltar que o fenômeno descrito acima não é peculiar à língua japonesa. No português do Brasil, frequentemente vemos esse fenômeno como é o caso em que dois amigos se cumprimentam dizendo "E ai?" que pode virar "E aê?" e depois "Eê?".

Uma evolução da fusão de vogais é a perda do alongamento da vogal final. Em Kagoshima, /hai/ cinza é dito /he/, sem alongamento.

\section{Teoria de distribuição periférica de formas dialetais - hôgen shûken ron}

Como já dito anteriormente, é comum a ocorrência de características dialetais do Leste no Oeste e em locais geograficamente distantes. Porém, nem tudo pode ser explicado como casos de empréstimos. Um exemplo é que o acento de Tôkyô pode ser visto no Oeste, como em San'in (Shimane, Tottori e Yamaguchi), Shikoku e Kyûshû.

"Uma hipótese que tem sido dada pra explicar o mistério diz que a língua do tipo oriental estava espalhada por todo o Japão desde o início, e desenvolvimentos posteriores das

10 A região de Kinki é composta pelas províncias de Ôsaka, Kyôto, Hyôgo, Nara, Mie, Gifu e Wakayama. 
características ocidentais nas capitais antigas do Japão ocidental, Nara e Kyoto, se difundiram daí." (SHIBATANI, 1990, p. 200) ${ }^{11}$

Assim, as características da região de Kyôto se desenvolveram e se espalharam. O precursor da hipótese desta teoria no Japão, chamada de hôgen shûken ron (方言周圈 論), foi Yanagita Kunio (1875-1962). O pesquisador coletou e estudou várias palavras locais para caracol e descobriu que formas novas eram encontradas em Kyôto e nas vizinhanças, enquanto antigas formas eram encontradas à medida que se afastava do antigo centro cultural (SHIBATANI, 1990, p. 200-201). Assim como quando uma pedra é atirada na água e do ponto onde a pedra cai são formadas ondas com propagação radial, quando novas formas ou palavras são criadas e propagadas, se sobrepõem as antigas e à medida que se afastam, perdem força, onde é comum manterem as formas originais e consequentemente mais antigas.

A situação foi ilustrada na figura 3 por Yanagita e foi chamado de kagyûkô (蝸 牛考). Na figura, a forma retangular representa a ilha central. O centro de propagação é representado pela estrela e a propagação da palavra "caracol" que é conhecido como dedemushi; maimai; katatsumuri; tsuburi; namekuji do centro para a periferia (SUZUKI, HAYASHI, et al., 1995, p. 255).

\section{Oposição centro periferia:}

Algumas características podem ser descritas a partir da oposição centro-periferia de acordo com a Teoria da distribuição periférica de Yanagita.

\subsection{Variações fonéticas:}

\subsubsection{Palatalização das fricativas}

Nos dialetos centrais há a palatalização da fricativa /s/ antes de /i/ e não antes de /e/. Ou seja, é realizado [fi] e [se]. Entretanto, acredita-se que havia a palatalização do /s/ diante de /e/ até século XV e a combinação [ $\left.\int \mathrm{e}\right]$ permanece não apenas a área periférica como nas regiões de Kyûshû, Tôhoku, Hokuriku e algumas áreas de Shikoku, mas também as nas vizinhanças de Kyôto e algumas partes de Ôsaka, Mie e Shiga. Nas áreas citadas, sensei é pronunciado / $\mathrm{fen} \int \mathrm{ei} /$ (SHIBATANI, 1990, p. 202).

A palatalização é vista no português também. Com exceção dos leitores que venham de algumas regiões do nordeste, experimentem pronunciar a família do “T”. Não pronunciamos [ta], [te], [ti], [to], [tu] e sim [ta], [te], [tfi], [to], [tu].

11 "One hypothesis that has been advanced toward explaining the mystery contends that the Easterntype language was spread all over Japan at the beginning, and later developments of the Western characteristics in the old capitals in Western Japan, Nara and Kyoto, spread outward." 
Em Kyûshû, a palatalização do alveo-palatal antes de /e/ é comum.

\begin{tabular}{|c|c|c|}
\hline Tôkyô & Kyûshû & Sig. \\
\hline$[$ mite $]$ & $[$ mit $] \mathrm{e}]$ & olhar (flexionado) \\
\hline$[$ sode $]$ & {$[$ sodze $]$} & manga (roupa) \\
\hline
\end{tabular}

\subsubsection{Velar labializada}

O empréstimo de uma grande quantidade de palavras chinesas levou à introdução de novos tipos silábicos no japonês, [kwa] e [gwa]. Incorporados e estabilizados a camada lexical sino-japonesa até o século XVII tornando-se em [ka] e [ga] em Kyôto. Porém, o som foi preservado em algumas partes de Kyôto, algumas áreas periféricas de Tôhoku e na maior parte de Kyûshû etc.

\begin{tabular}{|c|c|l|}
\hline Tôkyô & Kyôto, Tôhoku e Kyûshû & \multicolumn{1}{c|}{ Significado } \\
\hline$[$ kadzi $]$ & {$[$ kwadzi $]$} & incêndio \\
\hline$[$ kadzi $]$ & {$[$ kadzi $]$} & afazeres domésticos \\
\hline
\end{tabular}

Em certas partes da ilha próxima a Kyûshû, a labialização da velar se desenvolveu de tal forma que passaram a se pronunciar $/ \mathrm{kwa} /$ como $/ \mathrm{pa} /$. Assim, / $\mathrm{kwa} / \mathrm{virou} / \mathrm{ka} / \mathrm{em}$ algumas localidades e em outras virou /pa/ (SHIBATANI, 1990, p. 203). Assim como a palavra "água" originada do latim aqua *[akwa] se tornou [apa] na língua romena.

\subsubsection{Combinações com semivogal - vogal}

A semivogal /j/ aparece antes das vogais /a/,/u/ e /o/ como em /ja/;/ju/;/jo/, a semivogal /w/, atualmente, só é visto antes do /a/ como em /wa/. Por isso, os verbos com o radical terminado em /w/, o som aparece na flexão negativa, veja o exemplo do verbo lavar (arau), abaixo.

\begin{tabular}{|c|c|}
\hline Antigamente & Atualmente \\
\hline arawimasu & ara(w)imasu \\
\hline arawu & ara(w)u \\
\hline arawanai & arawanai \\
\hline araweba & ara(w)eba \\
\hline
\end{tabular}


Antigamente, além da grafia do wo que hoje é usado somente para marcar o acusativo, havia a gráfica para /wi/ e /we/.

\begin{tabular}{|c|c|c|c|c|}
\hline wa & wi & u & we & wo \\
\hline$わ$ & わ & - & 总 & を \\
\hline
\end{tabular}

A antiga combinação [wi], [we] e [wo] foi preservada em vários dialetos. Abaixo os dialetos e os sons preservados:

\begin{tabular}{|l|l|}
\hline Localidades & Sons \\
\hline dialetos de Takajôchô & wi e we \\
\hline Região de Tôhoku & {$[\mathrm{we}] /[\mathrm{w} \varepsilon]$ e [wo] } \\
\hline Região de San'in & {$[\mathrm{we}]$} \\
\hline Kyûshû / Tôhoku & {$[\mathrm{je}]$} \\
\hline
\end{tabular}

\subsubsection{Fricativas bilabiais}

Como já visto anteriormente quando falado do dialeto de Ryûkyû, na ilha principal a consoante $[\mathrm{p}]$ virou $[\varphi]$ que posteriormente virou [h], mas em algumas

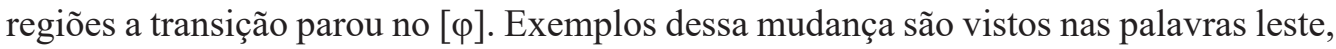
[higashi] na língua comum que é pronunciado [بigashi] nas regiões de Tôhoku e San'in. Outro exemplo é a palavra "cinzas", hai. Em Akita (Tôhoku), Miyazaki e Oita (Kyûshû) é pronunciado [甲e:] (SHIBATANI, 1990, p. 204)

Há no grego, um exemplo mais familiar aos falantes de língua portuguesa do [p] virar [f]. A palavra telefone era pronunciada com [p], [telep $\left.{ }^{\mathrm{h}} \mathrm{one}\right]$. Esse resquício pode ser visto ainda na escrita desta mesma palavra em inglês telephone.

\subsubsection{Fricativas/africadas contrastando na posição alveolopalatal}

Nos dialetos centrais contemporâneos, não há distinção na pronúncia de entre じ/zi/ e ぢ/di/; ず/zu/ e づ/du/. Os sons /zi/ e /di/ são pronunciados [ḋii], e/zu/ e /du/ são pronunciados [dzu] .Entretanto, o contraste existia no dialeto de Kyôto até o fim do século XVI quando aos poucos passou a perder a distinção. A distinção dos quatro sons conhecida como yotsugana (四つがな) e é preservada de várias maneiras nos dialetos atuais, mas com realizações distintas em cada local (SHIBATANI, 1990, p. 204). O dialeto de Tosa (Kôchi) é um dos dialetos que mantem a distinção dos quatro sons. 


\subsubsection{Nasalização antes de obstruentes sonoros (oclusivas e fricativas sonoras)}

Em certas regiões do Japão, oclusivas e fricativas sonoras como /b/, /d/, /z/ e /g/ são pré-nasalizadas. Há também no sul de Tôhoku, o vozeamento da consoante $/ \mathrm{k} / \mathrm{e} / \mathrm{t} /$. Assim, as palavras /ito/ (linha) e /ido/ (poço) são pronunciadas da mesma maneira, [ido]. Da mesma forma, /mato/ (alvo) e /mado/ (janela) são pronunciadas [mado]. Porém, no norte da mesma região, a distinção entre as palavras é mantida com a nasalização antes das consoantes $/ \mathrm{b} /, / \mathrm{d} /, / \mathrm{g} /$, e $/ \mathrm{z} /$, evitando-se assim, que as palavras de diferente significado sejam pronunciadas da mesma maneira. Por exemplo, a palavra /mato/ (alvo) é pronunciada [mado] e /mado/ (janela) é pronunciada [ma do]. Exemplos no caso da velar $/ \mathrm{g} / \mathrm{seriam}$ as palavras /taka/ (falcão) e /taga/ (aro) são pronunciadas, respectivamente, [taga] e [tạa] (SHIBATANI, 1990, p. 204-205). Abaixo a sistematização do fenômeno na região de Tôhoku.

$\begin{array}{lll}\text { Tōkyō } & \text { S. Tōhoku } & \text { N. Tōhoku } \\ {[-g-] \sim[-n-]} & {[-n-]} & {[-n-]} \\ {[-k-]} & {[-g-]} & {[-g-]} \\ {[-t-]} & {[-d-]} & {[-d-]} \\ {[-d-]} & {[-d-]} & {[-\sim d-]} \\ {[-b-]} & {[-b-]} & {[-\sim b-]} \\ {[-d z-]} & {[-d z-]} & {[-\sim d z-]}\end{array}$

\section{Shibatani (1990, p. 205)}

Shibatani (1990) afirma que o fenômeno descrito é resquício da articulação usada até meados do século XV em Kyôto. E esse mesmo fenômeno foi mantido em Kôchi. Na província que está localizada na região de Shikoku,/mado/ (janela) e /kabe/ (parede) são pronunciadas [ma do] e [ka be]. Além disso, a pré-nasalização se estende em consoantes oclusivas sonoras e fricativas sonoras em início de palavras. Por exemplo, / garasu/virou [ garasu], /gomi/ virou [ $\sim$ gomi].

\subsection{Variações Morfossintáticas:}

Nos aspectos morfossintáticos, Shibatani (1990) traz alguns casos em que a Teoria da distribuição periférica é vista. Um deles é a marcação de ênfase do acusativo (objeto direto). 
Nos dialetos centrais, a ênfase do objeto direto com finalidade contrativa é feito com o uso da partícula wa. Com exceção da partícula $g a$, anteriormente, assim como em outras partículas, era acrescida a partícula $w a[\varphi \mathrm{a}]$ após a partícula wo. Provavelmente, era pronunciada [woba].

Essa marca é preservada, sendo pronunciada [ba] em áreas periféricas como Tôhoku, Kyûshû e Amami - em Okinawa.

\section{Acento tonal}

Para entender como se dá a diferença de acentos tonais em japonês, é preciso entender o que vem a ser acento tonal e como ele é essencial para entender a existência de classes de palavras em japonês.

Em português temos o que se chama "acento tônico": Cada palavra tem uma sílaba tônica, que é a sílaba da palavra que é pronunciada de maneira mais forte (para entender a diferença, é só comparar as palavras "sábia", "sabia" e "sabiá").

Em japonês, as palavras podem ter o que chamamos de "acento tonal": Cada mora (ou sílaba, dependendo do lugar) tem um tom (que pode ser em geral "baixo" ou "alto", ou também "médio" em algumas regiões). Seguindo a convenção, os tons serão indicados com as letras "L" (low, ou baixo), "H" (high, ou alto) e "M" (medium, ou médio).

Assim como o acento tônico em português, o acento tonal pode ser usado para diferenciar palavras dentro de um dialeto (com a partícula sendo parte do sistema). Hashi, para pegar um exemplo, pode significar "palitinhos" (箸), “ponte" (橋) ou "beira” (端). Em Tôkyô, "palitinho" é falado com os tons HL(L) - o tom em parênteses indica o tom da partícula que pode seguir a palavra, como wa, ga ou qualquer que seja. Ponte é pronunciada com os tons $\mathrm{LH}(\mathrm{L})$, e beira com os tons $\mathrm{LH}(\mathrm{H})$. Ou seja, em isolamento, "ponte" e "beira" são pronunciadas da mesma forma, sendo a partícula que se segue a única diferença entre elas.

As combinações de tons não são nem uniformes ao longo do território japonês, nem aleatórias, mas seguem padrões típicos de cada região. Esses padrões, por sua vez, derivam de um sistema original.

Se pegarmos as palavras de duas moras (que nem hashi) como padrão, é possível perceber que as palavras em cada dialeto parecem pertencer a, no máximo, cinco grupos distintos - levando sempre em consideração que a última mora descrita abaixo é a da partícula (entre parênteses).

A região onde ainda se fazem mais distinções é nas ilhas Ibukijima, da província de Kagawa junto a Shikoku - as classes são bem definidas, com as palavras distinguidas em cinco grupos. Mas, nas outras regiões, o número de distinções é menor: Em Kyôto e regiões próximas (como Ôsaka, em Kansai), os dialetos fazem quatro distinções, juntando duas das classes (as que chamamos de classe 2 e classe 3 na tabela abaixo). Sora (de céu) e ame (de chuva) não são pronunciados com os mesmos tons. 
Em Tôkyô, o número de distinções cai para três, fazendo não só a mesma junção das classes 2 e 3 que é feita em Kyôto, mas eliminando as distinções entre as classes 4 e 5. Sora (de céu) e ame (de chuva), diferentemente de Kyôto, são pronunciados com os mesmos tons.

Em Kagoshima, na ilha de Kyûshû, o número de distinções cai para apenas duas - mas com um recorte diferente. Lá, as classes 1 e 2 são pronunciadas de um jeito, e as classes 3, 4 e 5 de outro. Enquanto em Tôkyô ishi (significando pedra) e yama (significando montanha) são pronunciados com os mesmos tons, em Kagoshima isso não acontece; Em compensação, tori (significando pássaro) e ishi (significando pedra) têm os mesmos tons em Kagoshima, mas não em Tôkyô.

Por fim, além das regiões em que não há distinção alguma de tom (como em Sendai, na região de Tôhoku da ilha de Honshû), há lugares em que as palavras são todas pronunciadas com os mesmos tons, como em Miyakonojou, em Kyûshû, onde as palavras têm tom baixo e as partículas tom alto.

\begin{tabular}{|c|c|c|c|c|c|}
\hline & $\begin{array}{l}\text { Classe } 1 \\
\text { niwa, tori }\end{array}$ & $\begin{array}{c}\text { Classe } 2 \\
\text { ishi, kawa }\end{array}$ & $\begin{array}{l}\text { Classe } 3 \\
\text { yama, inu }\end{array}$ & $\begin{array}{c}\text { Classe } 4 \\
\text { kasa, sora }\end{array}$ & $\begin{array}{l}\text { Classe } 5^{12} \\
\text { ame, saru }\end{array}$ \\
\hline $\begin{array}{l}\text { Ibukijima } \\
(\text { Shikoku) }\end{array}$ & $\begin{array}{l}\mathrm{HH}(\mathrm{H}) \\
\mathrm{LH}(\mathrm{H})\end{array}$ & $\begin{array}{l}\mathrm{HH}(\mathrm{L}) \\
\mathrm{LH}(\mathrm{L})\end{array}$ & $\mathrm{HM}(\mathrm{M})$ & $\mathrm{LL}(\mathrm{H})$ & LL(H-L) \\
\hline $\begin{array}{c}\text { Kyôto } \\
\text { (Honshû) }\end{array}$ & $\mathrm{HH}(\mathrm{H})$ & \multicolumn{2}{|c|}{$\mathrm{HL}(\mathrm{L})$} & $\mathrm{LL}(\mathrm{H})$ & $\mathrm{LH}(\mathrm{L})$ \\
\hline $\begin{array}{c}\text { Tôkyô } \\
\text { (Honshû) }\end{array}$ & $\mathrm{LH}(\mathrm{H})$ & \multicolumn{2}{|c|}{$\mathrm{LH}(\mathrm{L})$} & \multicolumn{2}{|c|}{ HL(L) } \\
\hline $\begin{array}{c}\text { Kagoshima } \\
\text { (Kyûshû) }\end{array}$ & \multicolumn{2}{|c|}{$\mathrm{LH}(\mathrm{L})$} & \multicolumn{3}{|c|}{$\mathrm{LL}(\mathrm{H})$} \\
\hline $\begin{array}{c}\text { Miyakonojô } \\
\text { (Kyûshû) }\end{array}$ & \multicolumn{5}{|c|}{ LLH } \\
\hline
\end{tabular}

\section{Adaptado de Shibatani (1990, p. 212)}

Os diferentes sistemas de tom se comportam de forma parecida à teoria do caracol, em que o centro tem mais distinções (quatro, em Kyôto) e uma periferia com menos distinções (ou até mesmo sem elas. Segundo Shibatani (1990, p. 213-214) é possível que o centro seja mais conservador nesse caso em específico, com as periferias apresentando inovações - no caso, a erosão do sistema tonal.

12 Classe 1: 庭 (quintal, jardim), 鳥 (ave). Classe 2: 石 (pedra), 川 (rio). Classe 3: 山 (montanha), 犬 (cão). Classe 4: 傘 (guarda-chuva), 空 (céu). Classe 5: 雨 (chuva), 猿 (macaco). 
O mapa a seguir mostra como o sistema com mais distinções irradia do centro (no caso, Kyôto) e o número de distinções cai quanto mais se vai à periferia.

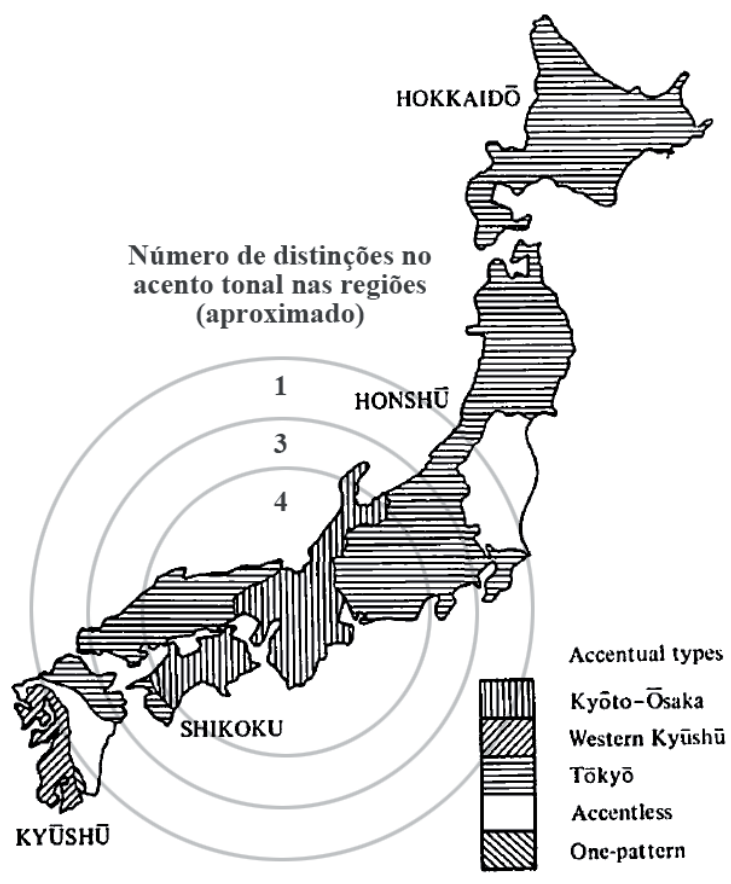

Mapa dos acentos tonais, adaptado de Shibatani (1990, p. 211)

\section{Extratos Dialetais}

\subsection{Dialeto de Tsugaru (Leste)}

O dialeto de Tsugaru é um dos dois dialetos da Província de Aomori, na região de Tôhoku conhecido também como zûzûben. O dialeto é assim conhecido, pois os seus falantes não fazem distinção entre / $\mathrm{ji} / \mathrm{e} / \mathrm{su} /$ e entre /dzi/ e /zu/, ou seja, entre as vogais /i/ e /u/. Assim, pronunciam sushi, susu (fuligem) e shishi (leão) da mesma forma. A pronúncia resultante é feita num local intermediário entre a vogal /i/ e /u/ (KUNO, 2006, p. 61). Mais exemplos abaixo: 


\begin{tabular}{|c|c|c|}
\hline \multicolumn{3}{|c|}{ Palavras com a mesma realização } \\
\hline chichi & tsutsu & tsuchi \\
\hline \multicolumn{2}{|c|}{ kaji } & \multicolumn{2}{|c|}{$\mathrm{kazu}^{13}$} \\
\hline
\end{tabular}

"No sul da região nordeste, / $\mathrm{u}$ /, /dzu/ e /tju/ ficam iguais, então jisan (velho) e jûsan (treze) também. Para habitantes de outras regiões, soam como zûzan" (KUNO, 2006, p. 61).

Na língua padrão, tanto o ritmo quanto o acento são centrados na noção da mora, que é uma unidade isométrica de ritmo - ou seja, todas as moras têm a mesma duração (diferente das sílabas em português, as quais têm durações diferentes dependendo da tonicidade). Existem quatro tipos de moras em língua japonesa: 1) V: Mora constituída por uma vogal só. 2) CV: Mora constituída por uma consoante seguida por uma vogal. Exemplo: か、き、く、け、こ.3) CjV: Mora constituída por uma consoante, uma semivogal, e uma vogal, como é o caso do きや、しや、みや etc. 4) C: Mora constituída por uma consoante (ou uma consoante nasal, ou uma consoante surda). É o caso do $h$ e do $\supset$, respectivamente, denominados hatsuon e sokuon. No entanto, segundo Kuno (2006) no dialeto de Tsugaru o hatsuon, sokuon e chôon não são menores que uma mora, ou seja, não seguem um ritmo moraico. Por isso, não há, na pronúncia do verbo pegar, toru na forma ta é pronunciado tota ao invés de totta. Pelo mesmo motivo, não há distinção koban (antiga moeda japonesa) e kôban (posto policial). Além disso, neste dialeto, há o fenômeno de acrescentar um som nasal (hatsuon) antes das consoantes $/ \mathrm{b} /, / \mathrm{d} / \mathrm{e} / \mathrm{g} /$ entre vogais, assim pronunciam kuda (tubo) e kunda (montou) de forma similar (p. 62).

Há ainda a sonorização das consoantes /k/e /t/, logo, sakeru (evitar) é pronunciado sageru (baixar), sendo /ge/ uma nasal velarizada como já foi descrito anteriormente.

Ainda segundo Kuno (2006), sendo natural que falantes de outras variedades dialetais não compreendam o dialeto de Tsugaru, houve um estímulo no ensino para o uso da língua comum em detrimento do zûzûben. Assim, as características dialetais acima descritas estão sendo perdidas e apenas os idosos as utilizam.

13 Na sequência: 乳 (seios), 筒 (cilindro), 土 (tsuchi), 火事 (incêncio), 数 (quantidade) 
Abaixo, algumas descrições morfológicas do dialeto de Tsugaru.

1) Forma adverbial dos adjetivos:

\begin{tabular}{|c|c|c|}
\hline $\begin{array}{c}\text { Língua } \\
\text { comum }\end{array}$ & Tsugaru & Sig. \\
\hline takakunaru & $\begin{array}{r}\text { tagagunaru } \\
\text { tagEgunaru }\end{array}$ & ficar caro \\
\hline
\end{tabular}

2) Formas de negações:

\begin{tabular}{|c|c|c|}
\hline $\begin{array}{c}\text { Língua } \\
\text { comum }\end{array}$ & Tsugaru & Sig. \\
\hline shinai & sanE, sanaæ & $\begin{array}{c}\text { neg. verbo } \\
\text { fazer }\end{array}$ \\
\hline sunE, sünE & $\begin{array}{c}\text { oginE ogïn } \\
\text { oginæ }\end{array}$ & $\begin{array}{c}\text { neg. verbo } \\
\text { acordar }\end{array}$ \\
\hline
\end{tabular}

\subsection{Dialeto de Tosa (Oeste)}

Como um exemplo do dialeto do Oeste, serão listadas algumas características da variedade falada na província de Kôchi, uma das províncias da ilha de Shikoku. Abaixo, uma breve descrição sobre o dialeto de Tosa.

O dialeto de Kôchi é um dos dialetos em que é feita a distinção entre os yotsugana. As sílabas /zi/ e /di/ são realizada [3i], [ dłi] respectivamente, apesar de o fenômeno estar se perdendo nas gerações mais novas. Na língua comum, é feita a distinção entre / zi/ e /zu/, mas não entre /dzi/ e /dzu/ (KUNO, 2006, p. 64).

Segundo Kuno (2006), assim como no dialeto de Tsugaru, /d/ e /g/ são precedidas de uma nasal anterior. Assim, karada (corpo) e karanda (enroscar), kago (cesto) kango (enfermagem) tem durações distintas (p.64).

Quanto à variação morfossintática, neste dialeto, ao invés de usar kara como partícula de causa/ motivo, usa-se $k i$.

\section{A: はりまや橋と写真撮りたいき、カメラ借りてもえい?}

A: Hariyamabashi to shishin toritai ki, kamera karitemo ee?

(Quero tirar foto da ponte Harimaya, por isso posso pegar a câmera emprestada?) 
B: それ、あたしのがやき、大事につかってよー。14

B: Sore, atashinogaya ki, daijini tsukatteyô.

(Essa câmera é minha, por isso, use com cuidado.)

Em Kôchi, usa-se outros auxiliares verbais ao invés do te-iru da língua comum.

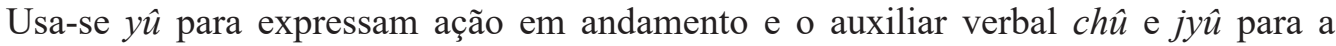
permanência do resultado de uma ação (KUNO, 2006, p. 65).
A: まだ雨は降りゆうろうか?
A: Mada ameha furi.yû rouka?
(Será que ainda está chovendo?)
B: さっきまで降りよったけんど、もうやんじゅうよ。15
B: Sakki made furi yotta kendo, mô yan'jyûu yo.
(Estava chovendo até agora pouco, mas já parou de chover.)

\section{Conclusão}

Procuramos, neste artigo, trazer informações amplas e resumidas sobre as variações dialetais da língua japonesa para os estudantes de japonês como língua estrangeira e pesquisadores que procurem uma introdução básica sobre o assunto. $\mathrm{O}$ que pode vir a auxiliar os alunos que porventura tenham dúvidas sobre quais são as possibilidades sobre variação dialetal no Japão explicando, por exemplo, que não há uma uniformidade no sistema tonal.

Para os falantes de língua portuguesa em geral, o apanhado apresentado acima pode servir para mostrar que muitos dos fenômenos que ocorrem em português - ou mesmo em japonês - não são exclusivos dessas línguas, mas tendências que ocorrem nas mais diferentes línguas do mundo.

Devido à limitação de espaço, não foi possível trazer mais detalhes além do que foi descrito acima, sendo necessária a publicação de mais pesquisas sobre o assunto em língua portuguesa, a fim de sanar a falta de material para alunos e pesquisadores de língua japonesa que estejam começando suas atividades e não tenham acesso a materiais em outras línguas.

14 Diálogo retirado do vídeo “Tosaben kôsa 01 (kihonhen sono 1)” 土佐弁講座01（基本編 そ 1), disponível em: <https://www.youtube.com/watch?v=uwd9IPowmfQ>

15 Diálogo retirado do vídeo “Tosaben kôsa 03 (kihonhen sono 3)” 土佐弁講座03（基本編 その3), disponível em: <https://www.youtube.com/watch?v=7VOEzdpnuu8> 


\section{Referências Bibliografias}

BAGNO, M. Nada na língua é por acaso: por uma pedagogia da variação linguística. São Paulo: Parábola Editorial, 2007.

CHAMBERS, J. K.; TRUDGILL, P. Dialectology. 2a . ed. Cambridge: Cambridge University Press, 1998.

KUNO, M. Os dialetos e os jovens. Estudos Japoneses, São paulo, v. 26, p. 59-66, 2006.

KUNO, M. Como se fala em Tokyo: Para uma proposição de dialeto metropolitano. Estudos Japoneses, São Paulo, v. 27, p. 7-27, 2007.

LINGUISTICS, N. I. O. J. L. A. Nihon Gengo Chizu. Nacional Institute of Japanese Language and Linguistics. Disponivel em: $<$ https://www.ninjal.ac.jp/publication/ catalogue/laj_map/>. Acesso em: 5 julho 2015.

MCWHORTER, J. Dialects-Subspecies of Species. In: MCWHORTER, J. The story of human language. [S.1.]: The Teaching Company, v. Part II, 2004. Cap. 14, p. $7-11$.

SHIBATANI, M. The languages of Japan. Cambridge: Cambridge University Press, 1990.

SUZUKI, K. et al. Gaisetsu Nihongo Gaku. 7ª ed. Tokyo: Meiji Shoin, 1995.

Sites consultados:

NACIONAL INSTITUTE FOR JAPANESE LANGUAGE AND LINGUISTIC. Nihon gengo chizu chizu gazou. Nacional Institute for Japanese Language and Linguistic, 2009. Disponivel em: $<$ https://www.ninjal.ac.jp/publication/catalogue/ laj_map/>. Acesso em: 05 Julho 2015. 